\title{
Ultrafast Growth of Uniform Multi-Layer Graphene Films Directly on Silicon Dioxide Substrates
}

\author{
Lijie Zhou ${ }^{1}$, Shuai Wei ${ }^{2}$, Chuanyang Ge ${ }^{2}$, Chao Zhao ${ }^{3}$, Bin Guo ${ }^{2}$, Jia Zhang ${ }^{2,4, *(D)}$ and \\ Jie Zhao ${ }^{4}$ \\ 1 School of Mechanical and Power Engineering, Harbin University of Science and Technology, No. 52, \\ Xuefu Road, Harbin 150080, China \\ 2 Key Laboratory of Microsystems and Microstructure Manufacturing, Ministry of Education, Harbin Institute \\ of Technology, No. 2 Yikuang Street, Harbin 150080, China \\ 3 College of Engineering, Swansea University, Fabian Way, Swansea SA1 8EN, UK \\ 4 State Key Laboratory of Robotics and System, Harbin Institute of Technology, No. 2 Yikuang Street, \\ Harbin 150080, China \\ * Correspondence: zhangjia@hit.edu.cn
}

Received: 23 May 2019; Accepted: 28 June 2019; Published: 1 July 2019

\begin{abstract}
To realize the applications of graphene in electronics, a large-scale, high-quality, and uniform graphene film should first be placed on the dielectric substrates. Challenges still remain with respect to the current methods for the synthesis graphene directly on the dielectric substrates via chemical vapor deposition, such as a low growth rate and poor quality. Herein, we present an ultrafast method for direct growth of uniform graphene on a silicon dioxide $\left(\mathrm{SiO}_{2} / \mathrm{Si}\right)$ substrate using methanol as the only carbon source. A $1 \times 1 \mathrm{~cm}^{2} \mathrm{SiO}_{2} / \mathrm{Si}$ substrate square was almost fully covered with graphene within $5 \mathrm{~min}$, resulting in a record growth rate of $\sim 33.6 \mu \mathrm{m} / \mathrm{s}$. This outcome is attributed to the quick pyrolysis of methanol, with the help of trace copper atoms. The as-grown graphene exhibited a highly uniform thickness, with a sheet resistance of $0.9-1.2 \mathrm{k} \Omega / \mathrm{sq}$ and a hole mobility of up to $115.4 \mathrm{~cm}^{2} / \mathrm{V} \cdot \mathrm{s}$ in air at room temperature. It would be quite suitable for transparent conductive electrodes in electrophoretic displays and may be interesting for related industrial applications.
\end{abstract}

Keywords: ultrafast growth rate; uniform graphene; silicon dioxide substrate

\section{Introduction}

Graphene is considered to be promising for use in future electronics [1]. To achieve its usage in electrical devices, first, large-scale, high-quality, and uniform graphene film should be placed on the dielectric substrate. Until now, many methods have been developed to grow graphene on metal surfaces and then transfer it onto a dielectric substrate for electrical applications [2-4]. However, the transfer process inevitably damages the film by introducing contaminations, wrinkles, and cracks [5]. Recently, graphene was successfully grown on a dielectric surface using the chemical vapor deposition (CVD) method [6]. However, one of biggest barriers is the very long growth duration (e.g., 1-82 h) [6-8], which means a low growth rate and limited potential in commercialization. For industrial production, a new method with a fast growth rate that produces an acceptable quality graphene is a must, which means decreased costs and energy consumption, and increased compatibility. Nevertheless, this goal is not easy to achieve, since there is a lack of metallic catalysts on the substrates needed to effectively pyrolyze the carbon source [9-12]. Liu et al. first reported the direct growth of graphene on a silicon dioxide $\left(\mathrm{SiO}_{2} / \mathrm{Si}\right)$ (i.e., $\left.1 \times 1 \mathrm{~cm}^{2}\right)$ substrate without any metallic catalysts, which took $3 \mathrm{~h}$ to be fully covered [9]. In this condition, the carbon precursors were quite difficult to decompose and nucleate on the dielectric substrates. Furthermore, the plasma-enhanced CVD method has been employed 
to accelerate decomposition of the carbon source (30-60 $\mathrm{min}$ ), but the resulting graphene was not uniform $[13,14]$. Many small graphene nanoclusters or nanocrystalline domains have been grown on dielectric substrates [13,14]. Recently, a trace of metal atoms (e.g., copper) were introduced into the reaction, working as catalysts to efficiently accelerate the decomposition of the carbon source [10-12]. Meanwhile, these metal atoms were continuously evaporating during the high temperature synthesis process, leading to a lack of residue on the grown graphene and substrates [10-12]. Significantly, a fully covered substrate (e.g., $1 \times 1 \mathrm{~cm}^{2}$ ) has been achieved in 30-60 min, and the quality of the graphene was comparable with those grown on metal surfaces [4]. This approach provides an additional opportunity for the direct growth of high-quality graphene directly on a dielectric substrate. Nevertheless, the maximum growth rate is $\sim 5.6 \mu \mathrm{m} / \mathrm{s}$, which is still far behind that of metals $(\sim 60 \mu \mathrm{m} / \mathrm{s})$ [15]. Therefore, there is still no fast method for the direct growth of graphene on dielectric substrates with an acceptable quality.

The hydrogen $\left(\mathrm{H}_{2}\right)$ gas has been proven to have a crucial role during CVD growth of graphene on metals $[16,17]$. It has two known roles: one is the etching of the as-grown graphene, which reduces the concentration of the active $C$ species on the catalyst surface and the other is its facilitation of the catalytic decomposition of carbon resources, which provides more active carbon species on the uncovered metal surface [16,17]. Vlassiouk et al. described the dual roles of $\mathrm{H}_{2}$ in the growth of graphene on $\mathrm{Cu}$ foil, which determined the graphene's crystallization quality, layer counts, domain morphologies, edge, growth rate, and stack patterns [17]. Moderate $\mathrm{H}_{2}$ concentrations favored a fast growth rate and high-quality graphene formations, while a low concentration resulted in no graphene [17]. Jung et al. observed that the growth rate of graphene increased as the partial pressure (equal to concentration) of $\mathrm{H}_{2}$ increased during the annealing process $[18,19]$. However, some researchers have found high-quality graphene with a fast growth rate was only achievable with a decreased $\mathrm{H}_{2}$ concentration, and could even occur without $\mathrm{H}_{2}$ present during the reaction [20]. As a result, this dilemma has not yet been clearly addressed with respect to the CVD method for the growth of graphene on metals, not to mention with respect to the direct growth of graphene on dielectric substrates.

Herein, we present an ultrafast method for the direct growth of uniform graphene on the $\mathrm{SiO}_{2} / \mathrm{Si}$ substrate by using methanol as the only carbon source. The role of $\mathrm{H}_{2}$ in the direct growth of graphene on the $\mathrm{SiO}_{2} / \mathrm{Si}$ substrate was first investigated. A $1 \times 1 \mathrm{~cm}^{2} \mathrm{SiO}_{2} / \mathrm{Si}$ substrate square was almost fully covered with graphene within $5 \mathrm{~min}$, resulting in a record growth rate of $\sim 33.6 \mu \mathrm{m} / \mathrm{s}$. This outcome has been attributed to the quick pyrolysis of methanol, with help of a trace of copper atoms. The as-grown graphene exhibited a uniform thickness with three layers with a sheet resistance of $0.9-1.2 \mathrm{k} \Omega / \mathrm{sq}$ and a hole mobility of up to $115.4 \mathrm{~cm}^{2} / \mathrm{V} \cdot \mathrm{s}$ in air at room temperature. These parameters are higher than those collected from graphene samples directly grown on dielectrics, and also are comparable to those of the CVD-grown graphene on nickel and copper films (Table 1). In addition, the as-grown graphene films would be quite suitable for transparent conductive electrodes in the electrophoretic displays, which require moderate conductivity and mobility. As a result, the proposal method possesses a competitive advantage in related industrial applications.

\section{Experimental Details}

\subsection{Direct Growth of Graphene on the $\mathrm{SiO}_{2} / \mathrm{Si}$ Substrate}

The growth was carried out in a horizontal tube furnace, in a manner that was the same as our previous paper [21]. A $1 \times 1 \mathrm{~cm}^{2} \mathrm{SiO}_{2} / \mathrm{Si}$ substrate was ultrasonically cleaned in acetone, isopropanol alcohol, and deionized water for $5 \mathrm{~min}$ each, and dried with pure nitrogen gas. Then it was loaded in the center of the horizontal tube furnace, above which a curved piece of $\mathrm{Cu}$ foil was suspended, as illustrated in Figure 1. The distance between the copper foil and the $\mathrm{SiO}_{2}$ substrate was controlled to be below $100 \mu \mathrm{m}$ to facilitate enough copper atoms travelling to the substrate after overcoming the gas flow and vacuum forces (Figure 1b) [10]. The tube was first pumped to $150 \mathrm{~m}$ Torr and maintained at the same pressure, while $10 \mathrm{sccm} \mathrm{H}_{2}$ was applied before annealing. The tube was then heated to 
$1020{ }^{\circ} \mathrm{C}$ at a rate of $15^{\circ} \mathrm{C} / \mathrm{min}$. After $20 \mathrm{~min}$ of annealing, the $\mathrm{H}_{2}$ was stopped. Then $10 \mathrm{sccm}$ Argon (Ar) was used as carrier gas for methanol to introduce the methanol vapor into the tube. The flow rate of the methanol vapor was calculated to be $\sim 1.56 \times 10^{-6} \mathrm{~mol} / \mathrm{min}$. After a desired duration, the furnace was naturally cooled to room temperature while applying $10 \mathrm{sccm} \mathrm{H}_{2}$ again.

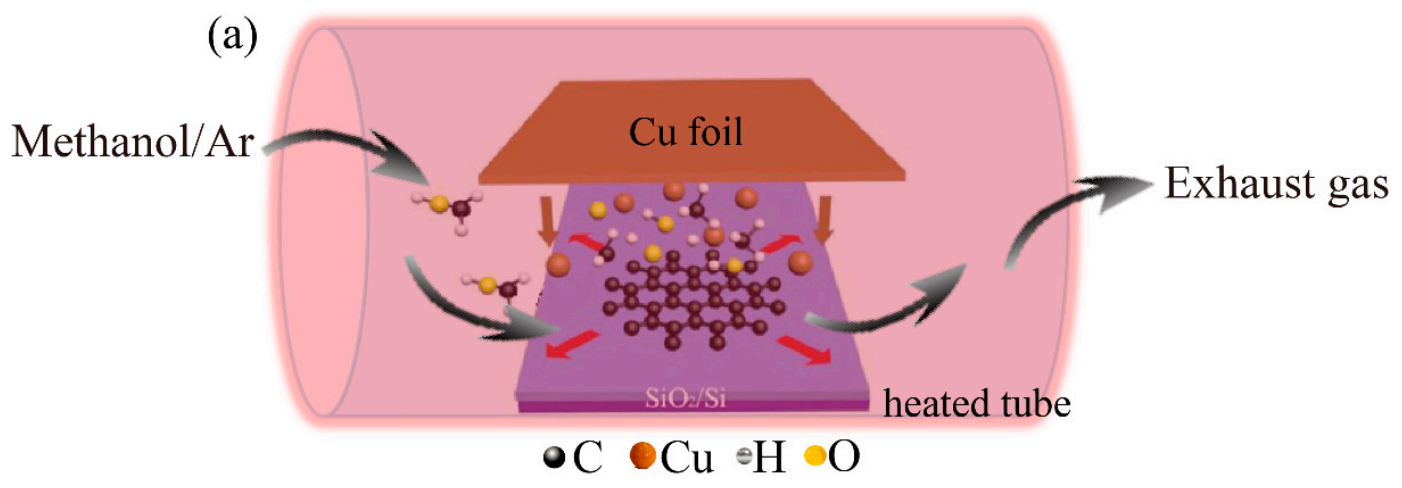

(b)

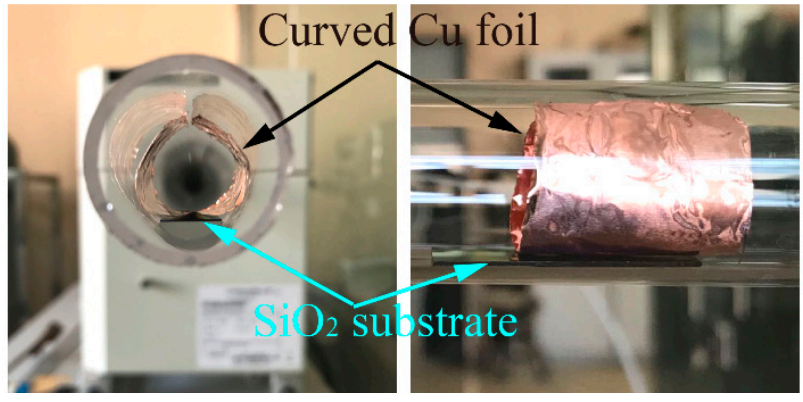

Figure 1. (a) Schematic illustration of the possible mechanism of the direct growth of graphene on the $\mathrm{SiO}_{2} / \mathrm{Si}$ substrate using methanol as the precursor. (b) Photography of curved suspended copper foil over the $\mathrm{SiO}_{2}$ substrate.

\subsection{Characterization}

The as-grown graphene was characterized using optical microscopy (DM4500P, Leica, Germany), transmission electron microscopy (TEM, Tacnai-G2 F30, Philips-FEI Inc., Netherlands, accelerating voltage of $300 \mathrm{kV}$ ), Raman spectroscopy (LabRAM XploRA, HORIBA JY, France, incident power of $\sim 1 \mathrm{~mW}$, pumping wavelength of $532 \mathrm{~nm}$ ), and atomic force microscopy (AFM, Dimension 5000, Bruker, Germany, tapping mode). The species that were used for the Raman, optical, and AFM tests were the as-grown graphene on the original $\mathrm{SiO}_{2} / \mathrm{Si}$ substrates without further annealing, unless addressed in other parts in this paper. The species used for TEM tests were from the transferred graphene on the copper grids.

\subsection{Fabrication of Field Effect Transistors for Electrical Measurements}

The electrical properties of the graphene were evaluated based on a field effect transistor (FET) configuration. The as-grown graphene film was first patterned into micro-ribbons. Then, $\mathrm{Cr} / \mathrm{Au}$ metal contacts $(10 / 50 \mathrm{~nm})$ were fabricated onto the micro-ribbons via thermal evaporation to form the bottom-gate FETs. The channel length $(L)$ and width $(W)$ were measured to be $\sim 27 \mu \mathrm{m}$ and $70 \mu \mathrm{m}$, respectively. To obtain better contact, the devices were thermally annealed at $200{ }^{\circ} \mathrm{C}$ in an $\mathrm{H}_{2} / \mathrm{Ar}$ (10/90 sccm) atmosphere for $30 \mathrm{~min}$. The electrical measurements were carried out in air at room temperature using a semiconductor analyser (Keithley 4200-SCS, Tektronix Inc., Beaverton, OR, USA).

\section{Results and Discussion}

Figure 1a illustrates the process of direct growth of graphene on the $\mathrm{SiO}_{2} / \mathrm{Si}$ substrate. In brief, a piece of $\mathrm{Cu}$ foil was suspended on the $\mathrm{SiO}_{2} / \mathrm{Si}$ substrate (Figure 1b), which releases copper atoms at 
high temperatures during the growth process [10]. Methanol vapor was carried into the tube by Ar gas and transported through the tube during growth (arrows in Figure 1a). It worked as the carbon source, which was quickly decomposed with the presence of the catalytic copper atoms. The suspended $\mathrm{Cu}$ foil would prevent copper contaminations in both the graphene film and $\mathrm{SiO}_{2} / \mathrm{Si}$ substrates [10]. According to Oshima's findings, approximately $70 \%$ of alcohols would be pyrolyzed within 3 min at temperatures above $1000{ }^{\circ} \mathrm{C}$ [22]. This could be further accelerated in the presence of metallic catalysts [23]. The high temperature (i.e., $1020^{\circ} \mathrm{C}$ ) and presence of the trace of copper atoms in the experiments may have responded to our ultrafast growth process. After the exclusion of stable methane in a previous study, methanol was found to be a good candidate for the carbon source. It can be a source of carbon and hydrogen and act as an inhibitor to amorphous carbon formation [24]. The previous study confirmed that there was no amorphous carbon that was observed in the CVD synthesis process when using methanol as precursor. This is quite different from other hydrocarbons, such as methane [24].

The catalytic pyrolysis of methanol is expected to generate a complex mixture, including hydrogen $\left(\mathrm{H}_{2}\right)$, carbon monoxide $(\mathrm{CO})$, carbon dioxide $\left(\mathrm{CO}_{2}\right)$, water and methane [23,24]. According to the thermodynamic equilibrium of the composition at high temperatures (e.g., $>750{ }^{\circ} \mathrm{C}$ ), the content of the main by-product, $\mathrm{H}_{2}$, is saturated at $\sim 68.5 \%$ [24,25]. The intermediate, $\mathrm{CO}_{2}$, will gradually reduce to $\mathrm{CO}$ and $\mathrm{H}_{2} \mathrm{O}$ due to the $\mathrm{H}_{2}$, leading to the final content of $\mathrm{CO}$ reaching up to $\sim 25.5 \%$. The residual $\mathrm{CO}_{2}$ and methane were below $5.5 \%$ and $0.5 \%$ in the composition, respectively, which was reasonably negligible in our experiment. Finally, the reaction of $\mathrm{CO}+\mathrm{H}_{2} \rightarrow \mathrm{C}+\mathrm{H}_{2} \mathrm{O}$ occurred at our set temperature (i.e., $1020^{\circ} \mathrm{C}$ ) with the copper catalyst, thus leading to highly active deposition of carbon radicals [25]. After the catalytic decomposition in the presence of the evaporated copper, those carbon radicals were nucleated on the $\mathrm{SiO}_{2} / \mathrm{Si}$ substrate at the low energy locations and formed the carbon nuclei and domains as prolonging the duration of the process (Figure 1a). The effective catalytic pyrolysis of methanol generated a large quantity of carbon radicals, leading to the faster growth of graphene in comparison to the traditional methods [9-12]. In addition, the reduction of the $\mathrm{H}_{2}$ in the feedback gas would reduce the etching at the edge of graphene domains, thereby increasing the growth rate further.

To reveal the effect of $\mathrm{H}_{2}$ on this newly developed process, a series of graphene samples were synthesized using different $\mathrm{H}_{2}$ concentrations. Figure $2 \mathrm{a}-\mathrm{d}$ show a series of Raman spectra that were collected from random points on each graphene sample grown using different $\mathrm{H}_{2}$ flow rates of 0 , 20,60 , and $100 \mathrm{sccm}$. The peaks at $\sim 1610 \mathrm{~cm}^{-1}$ and $\sim 2700 \mathrm{~cm}^{-1}$ were assigned to the $\mathrm{G}$ band and $2 \mathrm{D}$ band, respectively, which confirmed the presence of graphitic carbon [26]. Compared with the exfoliated graphene on the $\mathrm{SiO}_{2} / \mathrm{Si}$ substrate, the shift of $\mathrm{G}$ and 2D bands could be attributed to the stress in the graphene plane during growth [24,27]. Another peak at $\sim 1350 \mathrm{~cm}^{-1}$ was assigned to the D band, which was activated by the defects via an inter-valley double-resonance process [27]. Generally, the intensity ratio of the $\mathrm{D}$ band over the $\mathrm{G}$ band $\left(\mathrm{I}_{\mathrm{D}} / \mathrm{I}_{\mathrm{G}}\right)$ revealed the degree of the defects and the in-plane crystallite size $\left(\mathrm{L}_{\mathrm{a}}\right)$. The parameters that are derived from Raman spectra are accumulated in Figure $2 \mathrm{e}-\mathrm{g}$, which can be used to determine the influence of the $\mathrm{H}_{2}$ gas. The value of $\mathrm{I}_{\mathrm{D}} / \mathrm{I}_{\mathrm{G}}$ increased from $0.94 \pm 0.30$ to $1.79 \pm 0.67$ (Figure 2e) as the $\mathrm{H}_{2}$ flow increased from 0 to $100 \mathrm{sccm}$, suggesting the degradation of the quality of the graphene [26,27]. This can be attributed to the increase of the etching effect at high $\mathrm{H}_{2}$ concentrations, resulting in the formation of structural defects, vacancies, and fragments in-plane and at the edge of as-grown graphene $[16,17,28]$. The in-plane crystallite size of $\mathrm{L}_{\mathrm{a}}\left(\left(\mathrm{L}_{\mathrm{a}}\right)^{2}=(1.8 \pm 0.5) \times 10^{-9} \times \lambda_{\mathrm{L}}{ }^{2}\left(\mathrm{I}_{\mathrm{D}} / \mathrm{I}_{\mathrm{G}}\right)^{-1}\right)$ [29] reduced from $12.26 \pm 1.74 \mathrm{~nm}$ to $8.89 \pm 1.26 \mathrm{~nm}$, indicating less crystallinity at a larger $\mathrm{H}_{2}$ flow. In addition, the ratio of the $2 \mathrm{D}$ band over the $\mathrm{G}$ band $\left(\mathrm{I}_{2 \mathrm{D}} / \mathrm{I}_{\mathrm{G}}\right)$ gradually decreased from $1.74 \pm 0.43$ to $1.01 \pm 0.77$ (Figure $2 \mathrm{f}$ ). Previous results showed that the decreased value of $\mathrm{I}_{2 \mathrm{D}} / \mathrm{I}_{\mathrm{G}}$ may be caused by the increasing layer number and/or degradation of the quality of graphene $[25,30]$. In our study, all the graphene samples had a constant layer number, which was confirmed by the slightly variable full width at half maximum (FWHM) of the 2D band (i.e., $51-55 \mathrm{~cm}^{-1}$, as shown in Figure $2 \mathrm{~g}$ ) [26,30]. Therefore, the decrease of $\mathrm{I}_{2 \mathrm{D}} / \mathrm{I}_{\mathrm{G}}$ could be attributed to the degradation of the graphene. Overall, the Raman results suggested that the presence of $\mathrm{H}_{2}$ 
during the reaction would degenerate the as-grown graphene. According to the decomposition route of methanol, the by-product $\mathrm{CO}$ was reduced by the $\mathrm{H}_{2}$ to generate the carbon nuclei. This is the main driving force of the graphene growth on the $\mathrm{SiO}_{2}$ surface when using methanol as the only carbon source. Additionally, the exclusion of $\mathrm{H}_{2}$ in the carrier gas may also have reduced the etching effect and boost the growth rate remarkably.
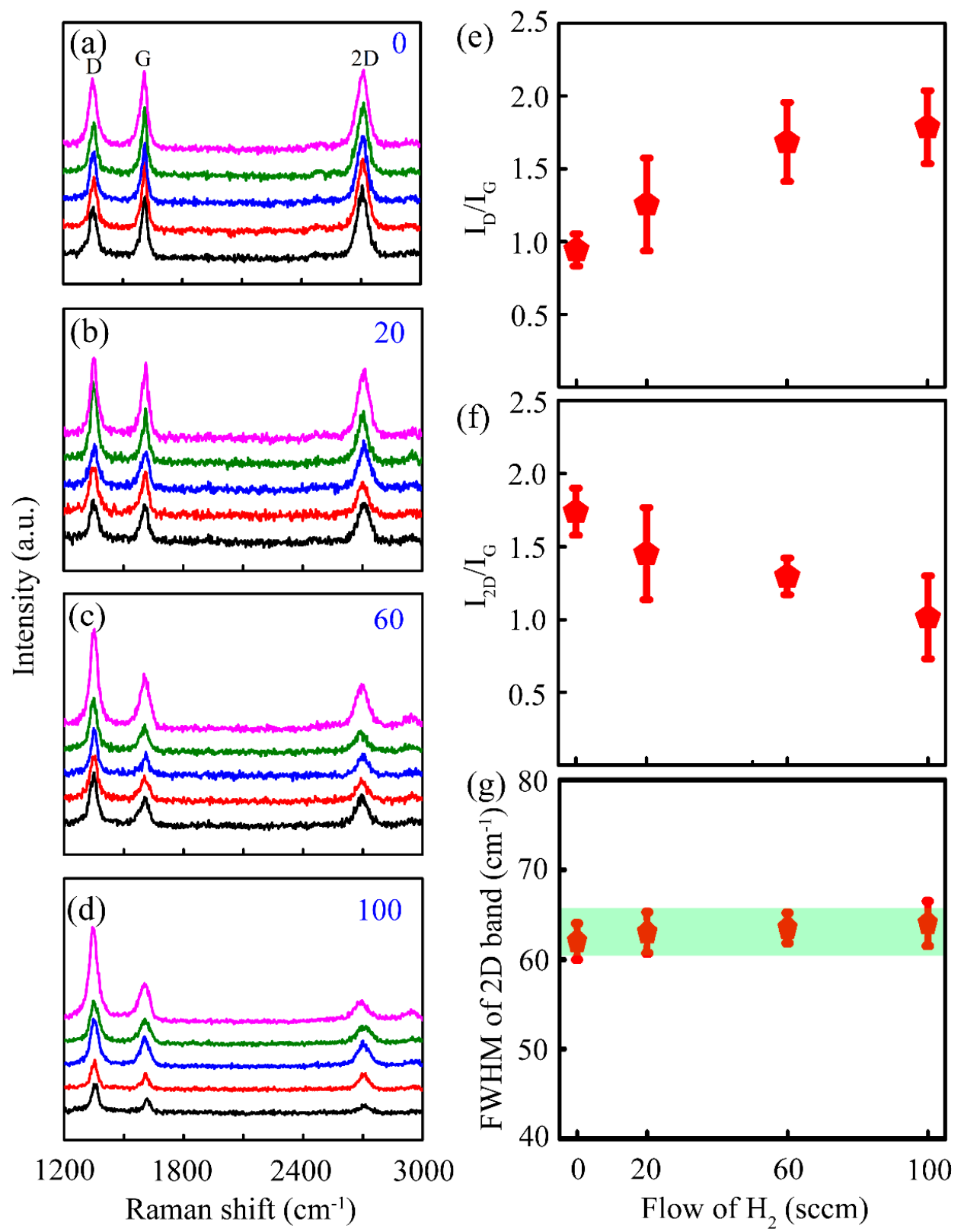

Figure 2. Effect of hydrogen on the properties of the as-grown graphene. Raman spectra of the graphene grown at $\mathrm{H}_{2}$ doses of $0,20,60$, and $100 \mathrm{sccm}$ for $(\mathbf{a}-\mathbf{d})$, respectively. The five different colored curves represent Raman signal collected from five different points on each graphene. The details derived from (a-d), (e) $\mathrm{I}_{\mathrm{D}} / \mathrm{I}_{\mathrm{G}},(\mathbf{f}) \mathrm{I}_{2 \mathrm{D}} / \mathrm{I}_{\mathrm{G}}$, and (g) and full width at half maximum (FWHM) of the $2 \mathrm{D}$ band, respectively.

Furthermore, we have investigated the morphological evolution of graphene film on the $\mathrm{SiO}_{2} / \mathrm{Si}$ substrate by varying the growth duration. The optical images of graphene films that were obtained by various growth durations $(0.5-30 \mathrm{~min})$ are shown in Figure 3. A large quantity of graphene flakes with an average size of $2-6.5 \mu \mathrm{m}$ appeared in the first $0.5 \mathrm{~min}$ (Figure 3a). The enlarged optical image 
(Figure 3a, inset) shows the approximately hexagonal shape of the graphene domain. Some flakes quickly extended the size to 20-36 $\mu \mathrm{m}$ in the following 2 min (Figure 3b, inset) and merged with adjacent ones within a further $2.5 \mathrm{~min}$ (Figure 3c). As the flakes grew in size, a large quantity of new nuclei was deposited on the uncovered area of the $\mathrm{SiO}_{2}$ substrate, resulting in the limitation of further growth of the graphene flake. As a result, the numerous nuclei were responsible for our ultrafast growth rate. The substrate was almost fully covered by the graphene film within 5 min (Figure 3c), resulting in an average growth rate of $\sim 33.6 \mu \mathrm{m} / \mathrm{s}$. To the best of our knowledge, this is the highest growth rate that has ever been reported for the direct growth of uniform graphene film on a SiO $2 / S i$ surface [9-12,15]. Further prolonging the growth duration, the graphene film tended to form a uniform film, considering the same reflection in the optical images (Figure $3 d-h$ ). Therefore, the thickness (analogous to layer number) of graphene remained unchanged after 5 min growth. This behavior is analogous to the growth of graphene film on $\mathrm{Cu}$ foils using alcohols in consideration of a continuous supply of the precursor and copper atoms [31].
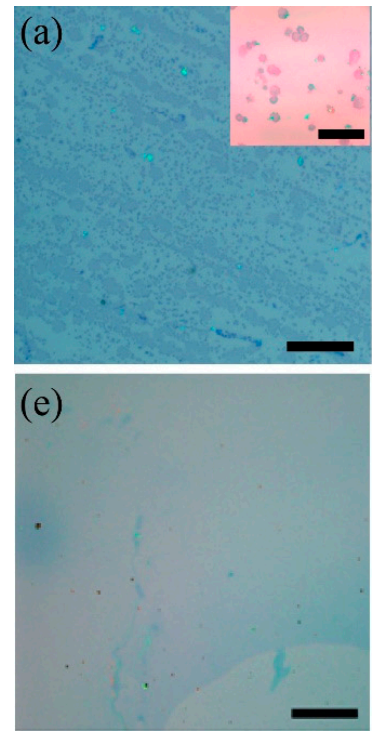
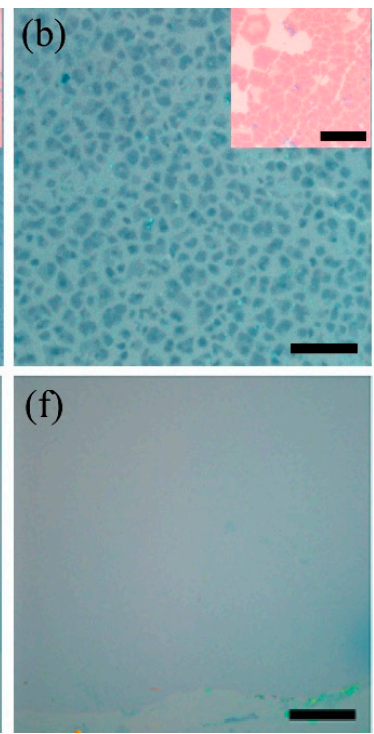
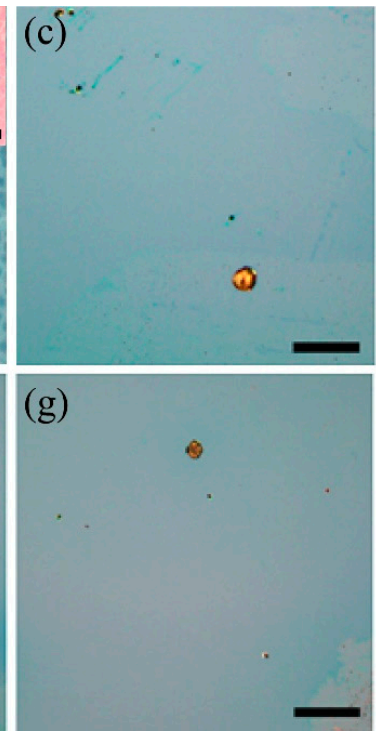

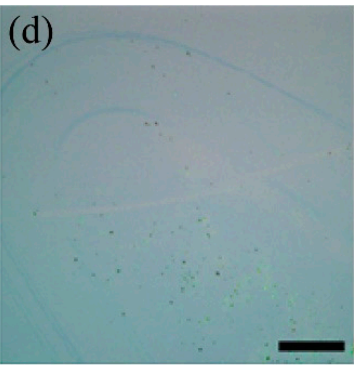

(h)

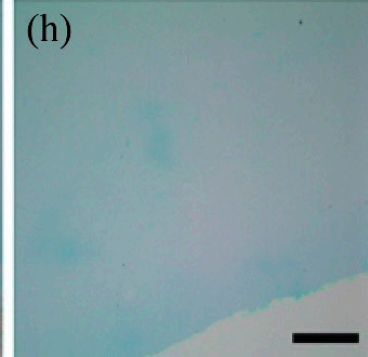

Figure 3. Optical images of the graphene that was directly grown on the $300 \mathrm{~nm} \mathrm{SiO} / 2 \mathrm{Si}$ substrate with respect to the growth durations of $(\mathbf{a}-\mathbf{h}) 0.5,2.5,5,10,15,20,25$, and $30 \mathrm{~min}$. The scale bar in the inset image in $(\mathbf{a}, \mathbf{b})$ are $20 \mu \mathrm{m}$, while the others are $200 \mu \mathrm{m}$.

The systematical Raman measurements revealed the quality, layer number, and defects of graphene samples with different growth durations (Figure 4). The values in Figure 4 are the statistical data (average with error) from five random spectra (points) of each graphene sample. The $\mathrm{I}_{\mathrm{D}} / \mathrm{I}_{\mathrm{G}}$ increased a little at first and then uniformly decreased down to $0.94 \pm 0.11$ (Figure 4a), reflecting the constantly improved crystallization of the graphene film as the growth duration increased. This could be attributed to the restoration of the $s p^{2}$-hybrid structure in-plane during the high temperature annealing process, which was also used to restore the graphene oxide [32]. Nevertheless, the value of $\mathrm{I}_{\mathrm{D}} / \mathrm{I}_{\mathrm{G}}$ was still larger than that measured in graphene grown with a long duration or on the metals. This could be attributed to the lack of sufficient metallic catalysts to completely pyrolyze methanol in a short time, resulting in many structural defects in the graphene. The average $\mathrm{I}_{\mathrm{D}} / \mathrm{I}_{\mathrm{G}}$ of the graphene samples that were grown with 30 min was much smaller than that measured in the reduced graphene oxide and some of the CVD-grown samples [33-35]. This indicates that the obtained graphene is more suitable for electronic applications than the reduced graphene oxide and some CVD-grown graphene [33-35]. Additionally, the improvement in quality was confirmed by the increase of $\mathrm{I}_{2 \mathrm{D}} / \mathrm{I}_{\mathrm{G}}$ from $0.1 \pm 0.002$ to $1.86 \pm 0.24$ (Figure $4 \mathrm{~b}$ ). Simultaneously, these values indicated a multilayer feature of the as-grown graphene, considering that it was usually above 2 in the single-layer graphene [27,30]. In addition, the FWHM(2D) fluctuated slightly at $55.3 \pm 1.92 \mathrm{~cm}^{-1}$ (Figure $4 \mathrm{c}$ ), which was similar to the previous 
results $\left(56.2 \pm 1.6 \mathrm{~cm}^{-1}\right)$ in three-layer exfoliated graphene [27]. It was almost confirmed to be three layers of as-grown graphene [27].
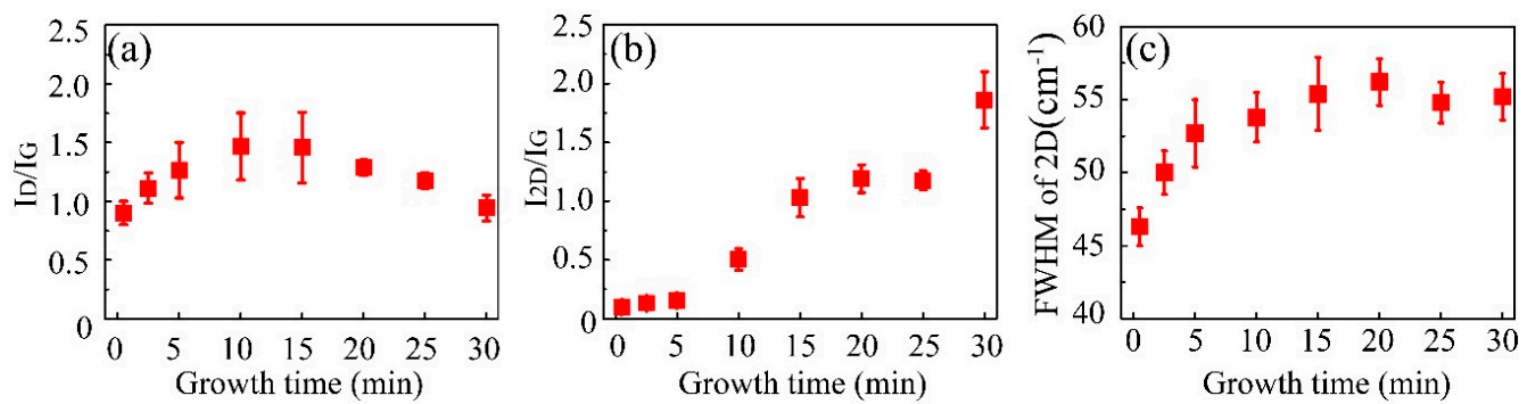

Figure 4. Detailed parameters derived from the Raman spectra of the graphene that was directly grown on the $300 \mathrm{~nm} \mathrm{SiO}_{2} / \mathrm{Si}$ substrate (a) $\mathrm{I}_{\mathrm{D}} / \mathrm{I}_{\mathrm{G}}$ (b) $\mathrm{I}_{2 \mathrm{D}} / \mathrm{I}_{\mathrm{G}}$, and (c) FWHM (2D), respectively.

AFM and TEM measurements were performed to determine the layer feature of the graphene films. The thicknesses of the graphene film at the growth durations of 5 30 min were measured to be in the range of 1.5-2.0 nm (Figure 5a shows a thickness of $1.5 \mathrm{~nm}$ ), which indicates a three-layer feature, considering the deviation in the AFM measurements [36]. Furthermore, the high-resolution TEM image at the back-folded edge (Figure $5 b, c$ ) of each graphene sample clearly shows a three-layer feature. A selected area electron diffraction (SAED) pattern has been applied to investigate the crystallographic pattern and orientation of the graphene. A typical SAED image (Figure 5d) shows two sets of hexagonal diffraction patterns, indicating that there is rotational stacking within the region measured [37]. The rotation of the diffraction pattern is determined by many features, such as intrinsic rotational stacking, back-folding of edges, and overlapping domains [37]. Herein, the rotation has been solely attributed to back-folding, considering that there were only two sets of patterns in the SAED images, indicating the single crystal feature of the selected areas [37]. The lattice constant was calculated to be $0.2468 \mathrm{~nm}$ from the SAED patterns (Figure 5d), which fit the graphene lattice of $0.247 \mathrm{~nm}[38]$.
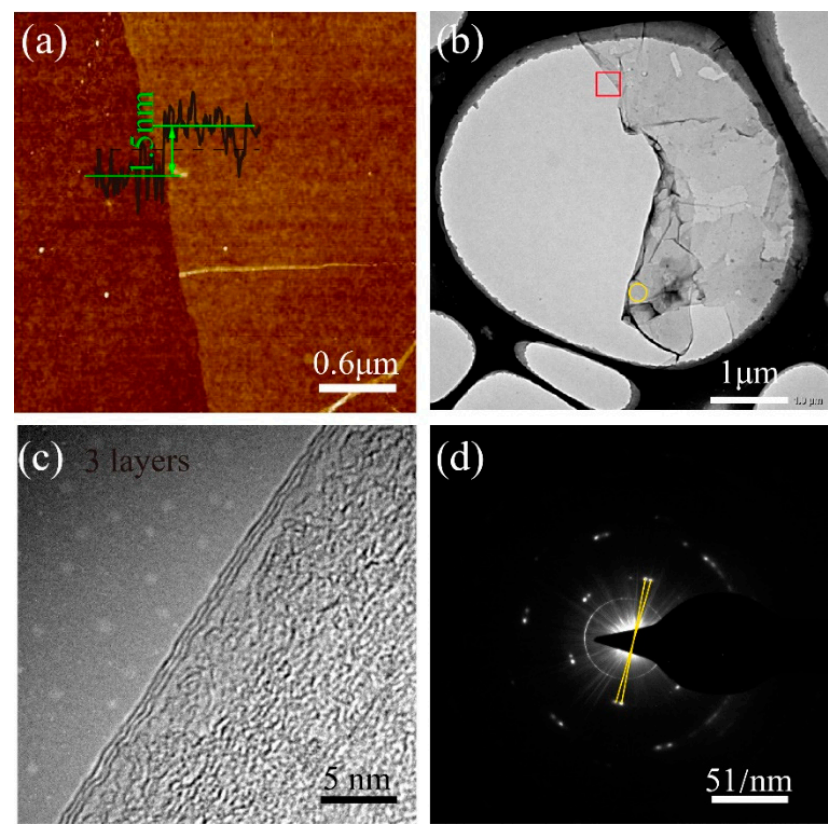

Figure 5. Characterization of the as-grown graphene film that was grown in $30 \mathrm{~min}$. (a) A typical atomic force microscopy (AFM) image with the height of the cross-section. (b) Low-magnification TEM image. (c) High-resolution TEM image at the back-folded edges (red box in b), identifying a trilayer graphene. (d) Selected area electron diffraction (SAED) pattern (yellow circle in b) at normal incidence. 
To evaluate the electrical properties of the as-grown graphene, bottom-gated field effect transistors (FETs) were made. The inset image in Figure 6a shows the FET device's configuration, in which the graphene works as a channel material. Figure 6a shows a typical transfer property (current of source-drain vs voltage applied on the gate Ids-Vgs) of the FET devices. The Ids decreased uniformly with a positive shifting of the gate voltage and a neutrality point at approximately $30 \mathrm{~V}$. It demonstrated a typical electrical feature of graphene that is measured in air at room temperature. In addition, the corresponding output curve (Ids-Vds, Figure 6b) showed decreasing Ids as the gate voltage increased. Both of characteristics indicated a heavy hole doping (p-type) feature in the graphene. The appearance of a strong p-type doping feature (Figure 6) was possibly due to the adsorption of oxygen and water molecules, since there are a lots of oxygen-containing groups in the graphene plane $[7,10]$. The sheet resistances measured by the four-terminate devices were found to be in the range of $0.9-1.2 \mathrm{k} \Omega / \mathrm{sq}$, which is much smaller than some previous results [39-45] (Table 1), indicating the promised electrical conductivity. The carrier mobility was calculated according to the equation: $\mu=\left(\Delta I_{\mathrm{ds}} \cdot L / W\right) /\left(\Delta V_{\mathrm{gs}} \cdot V_{\mathrm{ds}} \cdot C_{\mathrm{ox}}\right)$, where, $C_{\mathrm{ox}}$ is the silica gate capacitance $\left(1.15 \times 10^{-8} \mathrm{~F} / \mathrm{cm}^{2}\right.$ for a gate oxide thickness of $300 \mathrm{~nm}$ ). As a result, the hole and electron mobility were approximately 115.4 and $13.7 \mathrm{~cm}^{2} / \mathrm{V} \cdot \mathrm{s}$, respectively, which are higher than those of graphene film grown on some dielectrics (Table 1) [21,41-43], and also were comparable to those of the CVD-grown graphene on nickel $[46,47]$ and copper films [48-50] (Table 1). In addition, the hole mobility has been improved at least five-fold compared to our previous results within the same growth duration [21]. Specifically, as-grown graphene films could be quite suitable for transparent conductive electrodes in electrophoretic displays, which require moderate conductivity and mobility. Further optimization parameters for growth should be investigated to improve the quality of graphene that is grown over a very short duration.
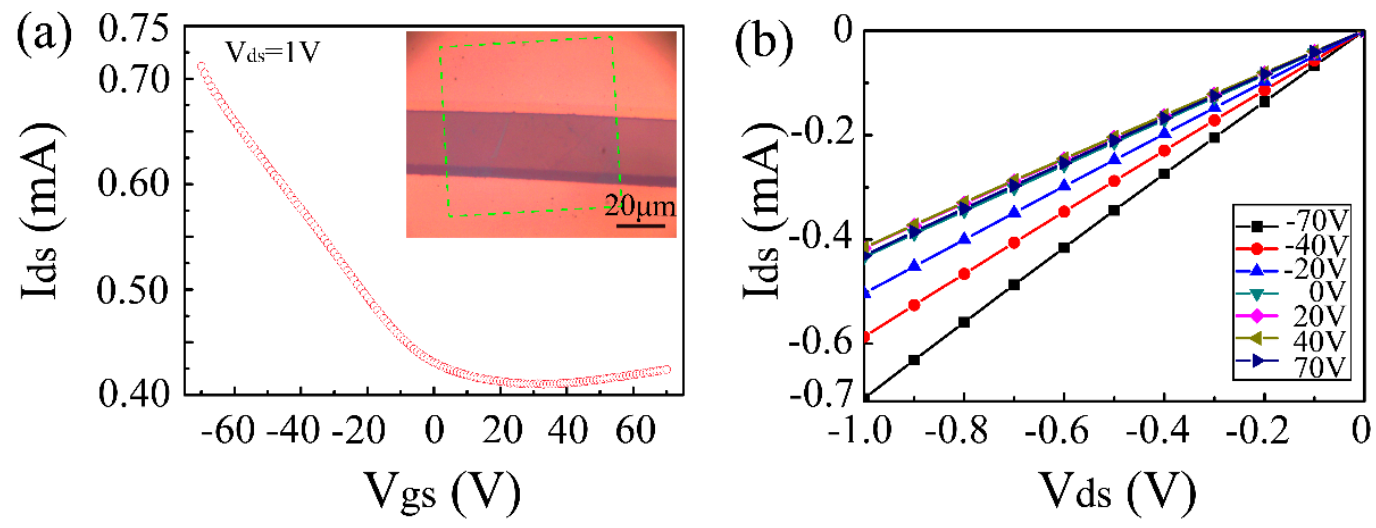

Figure 6. Electrical properties of the as-grown graphene. (a) Transfer characteristics (Ids-Vgs) of the field effect transistor (FET) device at Vds $=1 \mathrm{~V}$. Inset is an image of the device configuration with $70 \times$ $70 \mu \mathrm{m}^{2}$. (b) Output characteristics (Ids-Vds) of the graphene device at various gate voltages.

Table 1. Comparison of our results with the previous findings.

\begin{tabular}{cccc}
\hline Substrate & Hole Mobility $\left(\mathbf{c m}^{2} / \mathbf{V} \cdot \mathbf{s}\right)$ & Sheet Resistance $\mathbf{( k \Omega / s q})$ & Ref. \\
\hline $\mathrm{SiO}_{2}$ & 115.4 & $0.9-1.2$ & This work \\
$\mathrm{SiO}_{2}$ & $1.2-19.1$ & - & {$[21]$} \\
$\mathrm{Al}_{2} \mathrm{O}_{3}$ & 16 & $3.8-6.6$ & {$[41]$} \\
$\mathrm{quartz}^{\mathrm{SiO}} 2$ & 3.8 & - & {$[42]$} \\
$\mathrm{SiO}_{2}$ & 70 & 32.7 & {$[43]$} \\
$\mathrm{SiO}$ & 2 & $20-50$ & {$[44]$} \\
$\mathrm{Ni}$ & 120 & $6.6-8.5$ & {$[45]$} \\
$\mathrm{Ni}$ & $43-580$ & $1-2.6$ & {$[46]$} \\
$\mathrm{Cu}$ & - & 1.3 & {$[47]$} \\
$\mathrm{Cu}$ & $10-2000$ & $\sim 8.02$ & {$[48]$} \\
$\mathrm{Cu}$ & - & - & {$[49]$} \\
\hline
\end{tabular}




\section{Conclusions}

In summary, we have presented an ultrafast method for the direct growth of uniform graphene film on a $\mathrm{SiO}_{2} / \mathrm{Si}$ substrate. The methanol precursor was rapidly catalytically decomposed once it was introduced into the tube, leading to the ultrafast nucleation and growth of the graphene and a record growth rate of $\sim 33.6 \mu \mathrm{m} / \mathrm{s}$. Meanwhile, the exclusion of $\mathrm{H}_{2}$ in the carrier gas reduced the etching of the as-grown graphene domains, thereby improving the crystallization of the graphene. As a result, the trilayer graphene film was of a good quality, with a sheet resistance of $0.9-1.2 \mathrm{k} \Omega / \mathrm{sq}$ and hole mobility of up to $115.4 \mathrm{~cm}^{2} / \mathrm{V} \cdot \mathrm{s}$ in air at room temperature. These graphene films would be quite suitable for transparent conductive electrodes in the electrophoretic displays, which require moderate conductivity and mobility. Therefore, our method possesses a competitive advantage in related industrial applications.

Author Contributions: L.Z. and S.W. performed the experiments and data collection, analysis, and processing. C.G. carried out the characterization of TEM. C.Z. modified the language of manuscript. J.Z. is the project administration and funding acquisition, and also designed the experiments, prepared the manuscript. B.G. and J.Z. modified the manuscript and funding acquisition.

Funding: This project is supported by the National Key R\&D Program of China (Grant No. 2017YFB1300100), the National Natural Science Foundation of China (Grant No. 61771156, 51502059, 81571682), the Foundation for Innovative Research Groups of the National Natural Science Foundation of China (Grant No.51521003), the Heilongjiang Provincial Postdoctoral Science Foundation Grant (No. LBH-Z15053), the Open Found of Key Laboratory of Microsystems and Microstructure Manufacturing Ministry of Education (HIT) (No.2016KM010), the China Postdoctoral Science Foundation funded project (No. 2016T90279), and the Science and Technology Innovation Talents Special Fund of Harbin (No. 2016RQQXJ114).

Conflicts of Interest: The authors declare no conflicts of interest.

\section{References}

1. Wu, Y.; Farmer, D.B.; Xia, F.; Avouris, P. Graphene electronics: Materials, devices, and circuits. Proc. IEEE 2013, 101, 1620-1637. [CrossRef]

2. Kim, K.S.; Zhao, Y.; Jang, H.; Lee, S.Y.; Kim, J.M.; Kim, K.S.; Ahn, J.-H.; Kim, P.; Choi, J.-Y.; Hong, B.H. Large-scale pattern growth of graphene films for stretchable transparent electrodes. Nature 2009, 457, 706-710. [CrossRef]

3. Li, X.; Cai, W.; An, J.; Kim, S.; Nah, J.; Yang, D.; Piner, R.; Velamakanni, A.; Jung, I.; Tutuc, E.; et al. Large-area synthesis of high-quality and uniform graphene films on copper foils. Science 2009, 324, 1312-1314. [CrossRef]

4. Zhang, Y.; Zhang, L.; Zhou, C. Review of chemical vapor deposition of graphene and related applications. Acc. Chem. Res. 2013, 46, 2329-2339. [CrossRef]

5. Chen, Y.; Gong, X.-L.; Gai, J.-G. Progress and challenges in transfer of large-area graphene films. Adv. Sci. 2016, 3, 1500343. [CrossRef]

6. Chen, X.; Wu, B.; Liu, Y. Direct preparation of high quality graphene on dielectric substrates. Chem. Soc. Rev. 2016, 45, 2057-2074. [CrossRef]

7. Ning, J.; Wang, D.; Chai, Y.; Feng, X.; Mu, M.; Guo, L.; Zhang, J.; Hao, Y. Review on mechanism of directly fabricating wafer-scale graphene on dielectric substrates by chemical vapor deposition. Nanotechnology 2017, 28, 284001. [CrossRef]

8. Pham, V.P.; Jang, H.-S.; Whang, D.; Choi, J.-Y. Direct growth of graphene on rigid and flexible substrates: Progress, applications, and challenges. Chem. Soc. Rev. 2017, 46, 6276-6300. [CrossRef]

9. Chen, J.; Wen, Y.; Guo, Y.; Wu, B.; Huang, L.; Xue, Y.; Geng, D.; Wang, D.; Yu, G.; Liu, Y. Oxygen-aided synthesis of polycrystalline graphene on silicon dioxide substrates. J. Am. Chem. Soc. 2011, 133, 17548-17551. [CrossRef]

10. Kim, H.; Song, I.; Park, C.; Son, M.; Hong, M.; Kim, Y.; Kim, J.S.; Shin, H.-J.; Baik, J.; Choi, H.C. Copper-vapor-assisted chemical vapor deposition for high-quality and metal-free single-layer graphene on amorphous $\mathrm{SiO}_{2}$ substrate. ACS Nano 2013, 7, 6575-6582. [CrossRef]

11. Teng, P.-Y.; Lu, C.-C.; Akiyama-Hasegawa, K.; Lin, Y.-C.; Yeh, C.-H.; Suenaga, K.; Chiu, P.-W. Remote catalyzation for direct formation of graphene layers on oxides. Nano Lett. 2012, 12, 1379-1384. [CrossRef] 
12. Bi, H.; Sun, S.; Huang, F.; Xie, X.; Jiang, M. Direct growth of few-layer graphene films on $\mathrm{SiO}_{2}$ substrates, their photovoltaic applications. J. Mater. Chem. 2012, 22, 411-416. [CrossRef]

13. Wei, D.; Lu, Y.; Han, C.; Niu, T.; Chen, W.; Wee, A.T.S. Critical crystal growth of graphene on dielectric substrates at low temperature for electronic devices. Angew. Chem. Int. Ed. 2013, 52, 14121-14126. [CrossRef]

14. Wei, D.; Peng, L.; Li, M.; Mao, H.; Niu, T.; Han, C.; Chen, W.; Wee, A.T.S. Low temperature critical growth of high quality nitrogen doped graphene on dielectrics by plasma-enhanced chemical vapor deposition. ACS Nano 2015, 9, 164-171. [CrossRef]

15. Xu, X.; Zhang, Z.; Qiu, L.; Zhuang, J.; Zhang, L.; Wang, H.; Liao, C.; Song, H.; Qiao, R.; Gao, P.; et al. Ultrafast growth of single-crystal graphene assisted by a continuous oxygen supply. Nat. Nanotechnol. 2016, 11, 930-935. [CrossRef]

16. Zhang, X.; Wang, L.; Xin, J.; Yakobson, B.I.; Ding, F. Role of Hydrogen in Graphene Chemical Vapor Deposition Growth on a Copper Surface. J. Am. Chem. Soc. 2014, 136, 3040-3047. [CrossRef]

17. Vlassiouk, I.; Regmi, M.; Fulvio, P.; Dai, S.; Datskos, P.; Eres, G.; Smirnov, S. Role of hydrogen in chemical vapor deposition growth of large single-crystal graphene. ACS Nano 2011, 5, 6069-6076. [CrossRef]

18. Jung, D.H.; Kang, C.; Kim, M.; Cheong, H.; Lee, H.; Lee, J.S. Effects of hydrogen partial pressure in the annealing process on graphene growth. J. Phys. Chem. C 2014, 118, 3574-3580. [CrossRef]

19. Zhang, X.; Ning, J.; Li, X.; Wang, B.; Hao, L.; Liang, M.; Jin, M.; Zhi, L. Hydrogen-induced effects on the CVD growth of high-quality graphene structure. Nanoscale 2013, 5, 8363-8366. [CrossRef]

20. Jin, Y.; Hu, B.; Wei, Z.; Luo, Z.; Wei, D.; Xi, Y.; Zhang, Y.; Liu, Y. Roles of $\mathrm{H}_{2}$ in annealing and growth times of graphene CVD synthesis over copper foil. J. Mater. Chem. A 2014, 2, 16208-16216. [CrossRef]

21. Liu, N.; Zhang, J.; Qiu, Y.; Yang, J.; Hu, P.A. Fast growth of graphene on $\mathrm{SiO}_{2} / \mathrm{Si}$ substrates by atmospheric pressure chemical vapor deposition with floating metal catalysts. Sci. China Chem. 2016, 59, 707-712. [CrossRef]

22. Oshima, H.; Suzuki, Y.; Shimazu, T.; Maruyama, S. Novel and simple synthesis method for submillimeter long vertically aligned single-walled carbon nanotubes by no-flow alcohol catalytic chemical vapor deposition. Jpn. J. Appl. Phys. 2008, 47, 1982-1984. [CrossRef]

23. Haw, J.F.; Song, W.; Marcus, D.M.; Nicholas, J.B. The mechanism of methanol to hydrocarbon catalysis. Acc. Chem. Res. 2003, 36, 317-326. [CrossRef]

24. Gadipelli, S.; Calizo, I.; Ford, J.; Cheng, G.; Hight Walker, A.R.; Yildirim, T. A highly practical route for large-area, single layer graphene from liquid carbon sources such as benzene and methanol. J. Mater. Chem. 2011, 21, 16057-16065. [CrossRef]

25. Kaiser, P.; Unde, R.B.; Kern, C.; Jess, A. Production of liquid hydrocarbons with $\mathrm{CO}_{2}$ as carbon source based on reverse water-gas shift and Fischer-Tropsch synthesis. Chem. Ing. Tech. 2013, 85, 489-499. [CrossRef]

26. Zhang, J.; Hu, P.; Wang, X.; Wang, Z.; Liu, D.; Yang, B.; Cao, W. CVD growth of large area and uniform graphene on tilted copper foil for high performance flexible transparent conductive film. J. Mater. Chem. 2012, 22, 18283-18290. [CrossRef]

27. Malard, L.M.; Pimenta, M.A.; Dresselhaus, G.; Dresselhaus, M.S. Raman spectroscopy in graphene. Phys. Rep. 2009, 473, 51-87. [CrossRef]

28. Zhang, Y.; Li, Z.; Kim, P.; Zhang, L.; Zhou, C. Anisotropic hydrogen etching of chemical vapor deposited graphene. ACS Nano 2012, 6, 126-132. [CrossRef]

29. Tuinstra, F.; Koenig, J.L. Raman spectrum of graphite. J. Chem. Phys. 1970, 53, 1126-1130. [CrossRef]

30. Hao, Y.; Wang, Y.; Wang, L.; Ni, Z.; Wang, Z.; Wang, R.; Koo, C.K.; Shen, Z.; Thong, J.T.L. Probing layer number and stacking order of few-layer graphene by Raman spectroscopy. Small 2010, 6, 195-200. [CrossRef]

31. Zhao, P.; Kumamoto, A.; Kim, S.; Chen, X.; Hou, B.; Chiashi, S.; Einarsson, E.; Ikuhara, Y.; Maruyama, S. Self-limiting chemical vapor deposition growth of monolayer graphene from ethanol. J. Phys. Chem. C 2013, 117, 10755-10763. [CrossRef]

32. Tamboli, S.H.; Kim, B.S.; Choi, G.; Lee, H.; Lee, D.; Patil, U.M.; Lim, J.; Kulkarni, S.B.; Jun, S.C.; Cho, H.H. Post-heating effects on the physical and electrochemical capacitive properties of reduced graphene oxide paper. J. Mater. Chem. A 2014, 2, 5077-5082. [CrossRef]

33. Stankovich, S.; Dikin, D.A.; Piner, R.D.; Kohlhaas, K.A.; Kleinhammes, A.; Jia, Y.; Wu, Y.; Nguyen, S.T.; Ruoff, R.S. Synthesis of graphene-based nanosheets via chemical reduction of exfoliated graphite oxide. Carbon 2007, 45, 1558-1565. [CrossRef] 
34. Zhang, J.; Hu, P.; Zhang, R.; Wang, X.; Yang, B.; Cao, W.; Li, Y.; He, X.; Wang, Z.; O'Neill, W. Soft-lithographic processed soluble micropatterns of reduced graphene oxide for wafer-scale thin film transistors and gas sensors. J. Mater. Chem. 2012, 22, 714-718. [CrossRef]

35. Sun, J.; Chen, Y.; Priydarshi, M.K.; Chen, Z.; Bachmatiuk, A.; Zou, Z.; Chen, Z.; Song, X.; Gao, Y.; Rümmeli, M.H.; et al. Direct chemical vapor deposition-derived graphene glasses targeting wide ranged applications. Nano Lett. 2015, 15, 5846-5854. [CrossRef]

36. Shearer, C.J.; Slattery, A.D.; Stapleton, A.J.; Shapter, J.G.; Gibson, C.T. Accurate thickness measurement of graphene. Nanotechnology 2016, 27, 125704. [CrossRef]

37. Meyer, J.C.; Geim, A.K.; Katsnelson, M.I.; Novoselov, K.S.; Booth, T.J.; Roth, S. The structure of suspended graphene sheets. Nature 2007, 446, 60-63. [CrossRef]

38. Chan, K.T.; Neaton, J.B.; Cohen, M.L. First-principles study of metal adatom adsorption on graphene. Phys. Rev. B 2008, 77, 235430. [CrossRef]

39. Shin, H.J.; Choi, W.M.; Yoon, S.M.; Han, G.H.; Woo, Y.S.; Kim, E.S.; Chae, S.J.; Li, X.S.; Benayad, A.; Loc, D.D.; et al. Transfer-free growth of few-layer graphene by self-assembled monolayers. Adv. Mater. 2011, 23, 4392-4397. [CrossRef]

40. Kim, Y.-J.; Kim, S.J.; Jung, M.H.; Choi, K.Y.; Bae, S.; Lee, S.-K.; Lee, Y.; Shin, D.; Lee, B.; Shin, H. Low-temperature growth and direct transfer of graphene-graphitic carbon films on flexible plastic substrate. Nanotechnology 2012, 23, 344016. [CrossRef]

41. Zheng, S.; Zhong, G.; Wu, X.; D'Arsiè, L.; Robertson, J. Metal-catalyst-free growth of graphene on insulating substrates by ammonia-assisted microwave plasma-enhanced chemical vapor deposition. RSC Adv. 2017, 7, 33185-33193. [CrossRef]

42. Murakami, K.; Tanaka, S.; Hirukawa, A.; Hiyama, T.; Kuwajima, T.; Kano, E.; Takeguchi, M.; Fujita, J.-I. Direct synthesis of large area graphene on insulating substrate by gallium vapor-assisted chemical vapor deposition. Appl. Phys. Lett. 2015, 106, 093112. [CrossRef]

43. Kwak, J.; Chu, J.H.; Choi, J.-K.; Park, S.-D.; Go, H.; Kim, S.Y.; Park, K.; Kim, S.-D.; Kim, Y.-W.; Yoon, E.; et al. Near room-temperature synthesis of transfer-free graphene films. Nat. Commun. 2012, 3, 645. [CrossRef]

44. Yan, Z.; Peng, Z.; Sun, Z.; Yao, J.; Zhu, Y.; Liu, Z.; Ajayan, P.M.; Tour, J.M. Growth of bilayer graphene on insulating substrates. ACS Nano 2011, 5, 8187-8192. [CrossRef]

45. Kato, T.; Hatakeyama, R. Direct Growth of doping-density-controlled hexagonal graphene on $\mathrm{SiO}_{2}$ substrate by rapid-heating plasma CVD. ACS Nano 2012, 6, 8508-8515. [CrossRef]

46. Chen, Z.; Ren, W.; Liu, B.; Gao, L.; Pei, S.; Wu, Z.-S.; Zhao, J.; Cheng, H.-M. Bulk growth of mono- to few-layer graphene on nickel particles by chemical vapor deposition from methane. Carbon 2010, 48, 3543-3550. [CrossRef]

47. Reina, A.; Jia, X.; Ho, J.; Nezich, D.; Son, H.; Bulovic, V.; Dresselhaus, M.S.; Kong, J. Large area, few-layer graphene films on arbitrary substrate by chemical vapor deposition. Nano Lett. 2009, 9, 30-35. [CrossRef]

48. Wu, W.; Yu, Q.; Peng, P.; Liu, Z.; Bao, J.; Pei, S.-S. Control of thickness uniformity and grain size in graphene films for transparent conductive electrode. Nanotechnology 2012, 23, 035603. [CrossRef]

49. Zhang, B.; Lee, W.H.; Piner, R.; Kholmanov, I.; Wu, Y.; Li, H.; Ji, H.; Ruoff, R.S. Low-temperature chemical vapor deposition growth of graphene from toluene on electropolished copper foil. ACS Nano 2012, 6, 2471-2476. [CrossRef]

50. Luo, Z.; Lu, Y.; Singer, D.W.; Berck, M.E.; Somers, L.A.; Goldsmith, B.R.; Johnson, A.T. Effect of substrate roughness and feedback concentration on growth of wafer-scale graphene at atmospheric pressure. Chem. Mater. 2011, 23, 1441-1447. [CrossRef]

(C) 2019 by the authors. Licensee MDPI, Basel, Switzerland. This article is an open access article distributed under the terms and conditions of the Creative Commons Attribution (CC BY) license (http://creativecommons.org/licenses/by/4.0/). 